\title{
ARD
}

\section{Clinical features and risk factors of postsurgical gout}

E H Kang, E Y Lee, Y J Lee, Y W Song and E B Lee

Ann Rheum Dis 2008;67;1271-1275; originally published online 12 Nov 2007; doi:10.1136/ard.2007.078683

Updated information and services can be found at:

http://ard.bmj.com/cgi/content/full/67/9/1271

\section{These include:}

References This article cites 27 articles, 9 of which can be accessed free at: http://ard.bmj.com/cgi/content/full/67/9/1271\#BIBL

Rapid responses One rapid response has been posted to this article, which you can access for free at:

http://ard.bmj.com/cgi/content/full/67/9/1271\#responses

You can respond to this article at:

http://ard.bmj.com/cgi/eletter-submit/67/9/1271

Email alerting Receive free email alerts when new articles cite this article - sign up in the box at service the top right corner of the article

Topic collections Articles on similar topics can be found in the following collections

Genetics (1171 articles)

Degenerative joint disease (3031 articles)

Musculoskeletal syndromes (4621 articles)

\section{Notes}

To order reprints of this article go to:

http://journals.bmj.com/cgi/reprintform

To subscribe to Annals of the Rheumatic Diseases go to:

http://journals.bmj.com/subscriptions/ 


\title{
Clinical features and risk factors of postsurgical gout
}

\author{
E H Kang, E Y Lee, Y J Lee, Y W Song, E B Lee
}

- Supplementary tables 1 and 2 are published online only at http://ard.bmj.com/content/ vol67/issue9

Department of Internal Medicine, Seoul National University College of Medicine, Seoul, Korea; Medical Research Center, Seoul National University, Seoul, Korea

Correspondence to: E B Lee, Department of Internal Medicine, Seoul National University College of Medicine 28 Yongon-dong, Jongno-gu, Seoul, Korea 110-740; leb7616@snu.ac.kr

Accepted 1 November 2007 Published Online First 12 November 2007

\section{ABSTRACT}

Objectives: To investigate the clinical characteristics and risk factors of gout attacks that develop during the postsurgical period.

Methods: We enrolled 67 patients with gout who developed postsurgical gout and 67 controls who had histories of gout but did not develop gout attacks after surgery. Features of the postsurgical gout attacks were analysed and compared to those of presurgical gout attacks suffered by patients and controls. Demographics, medical backgrounds, laboratory data and surgical factors were compared between patients and controls in order to establish risk factors associated with postsurgical gout.

Results: The mean (SD) time interval to develop postsurgical gout was 4.2 (3.1) days. The attacks tended to involve lower extremity joints $(65 / 67,97.0 \%)$, usually the first metatarsophalangeal joint $(42 / 67,62.7 \%)$, and to affect more than one joint $(34 / 67,50.7 \%)$. The number of attacked joints was positively correlated with the total number of previously involved joints $(r=0.281$,

$p=0.026)$. The site of attacks had a preference for the previously affected sites. A history of cancer surgery $(p=0.002)$, elevated presurgical serum urate levels ( $\geqslant 9 \mathrm{mg} / \mathrm{dl} ; p=0.002$ ) and failure to administer colchicine prophylaxis $(p=0.008)$ were found to be risk factors for postsurgical gout.

Conclusions: Postsurgical gout tends to develop within 8 days after surgery. The site and number of involved joints reflect the features of gout attacks the patient suffered before surgery. Adequate presurgical control of serum uric acid levels and/or prophylactic administration of colchicine will help prevent gout attacks during the postsurgical period.

Gout is a recurrent inflammatory arthritis caused by deposition of urate crystals in joints or soft tissues. ${ }^{1}$ Despite recent progress in understanding its pathogenesis, the prevalence of gout has been increasing. ${ }^{2}$ It develops with various chronic diseases including hypertension, hyperlipidaemia, obesity, kidney diseases and cardiovascular diseases. ${ }^{14}$ Gout attack is extremely painful and is suggested to be precipitated by alcohol intake, a high purine diet, fasting, trauma and surgery. ${ }^{5-7}$

Since surgery is believed to agitate gout attack, early detection and management of postsurgical gout is important in several respects. First, a postsurgical gout attack is often mistaken for an infectious condition. This leads to unnecessary diagnostic and therapeutic interventions. ${ }^{8}$ Second, it often delays early ambulation that many operations require for the most favourable outcomes $^{9-11}$ and to reduce length of hospital stay. ${ }^{12}$ Third, postsurgical gout is a useful human gout model for studying the pathogenesis of gout, since daily monitoring of the patient is possible during the postsurgical period. Furthermore, a postsurgical gout attack was reported to develop in $17.2 \%$ of inpatient patients with gout after surgery. ${ }^{8}$ Except for two descriptive case series studies, ${ }^{8}{ }^{13}$ however, there have been no evidence-based clinical guidelines for postsurgical gout.

In this study, we explored the clinical characteristics and risk factors of postsurgical gout attacks. This study will help clinicians predict, recognise and manage such gout attacks more appropriately in the presurgical and postsurgical period.

\section{PATIENTS AND METHODS \\ Patients}

A total of 72 patients who developed postsurgical gout were identified from a list of 1543 surgical patients who had been consulted to by the Division of Rheumatology, Seoul National University Hospital, South Korea, between December 1999 and March 2006. Diagnosis of gout was made based on ascertainment of the presence of needle-shaped monosodium urate crystals in the affected joint fluid using polarised microscopy. Postsurgical gout attack was defined as an attack that developed within 20 days after a surgical procedure performed under general anaesthesia. ${ }^{8}$ Of the 72 patients, 67 had prior history of gout. These 67 patients were enrolled as cases for risk factor analysis.

\section{Controls}

A total of 67 gout patients who did not develop gout after a surgical procedure were identified through an electronic medical record system. Among 4309 patients who had hyperuricaemia at any one time, we could identify 390 patients who had a history of gout and underwent a surgical procedure under general anaesthesia in the same hospital during the same period of time as the patients who suffered postsurgical gout. Among these 390 patients, 67 patients experienced no postsurgical gout attack and had sufficient clinical information to analyse. These 67 patients were enrolled as controls for risk factor analysis.

\section{Collection of clinical data}

The institutional review board of the Seoul National University Hospital approved access to the medical records for this study. Structured consultation sheets completed by two of the authors (YWS and EBL) and medical records were used to retrieve relevant demographic and clinical data. For all patients, the following were collected: (1) demographic data including age, gender and body mass index (BMI; $\left.\mathrm{kg} / \mathrm{m}^{2}\right)$; (2) data on accompanying medical conditions, such as hypertension, diabetes, dyslipidaemia, renal insufficiency and cancer; (3) features of postsurgical gout attack, which consist of onset, distribution and the 
Table 1 Features of postsurgical gout attacks

\begin{tabular}{lc}
\hline & $\mathbf{n}=\mathbf{6 7}(\%)$ \\
\hline Duration of gout (years, mean (SD)) & $7.6(6.3)$ \\
Postsurgical period of gout attack (days, mean (SD)) & $4.2(3.1)$ \\
Involved joints at attack: & \\
Lower extremity involvement & $65(97.0)$ \\
First metatarsophalangeal joint & $42(62.7)$ \\
Ankle & $21(31.3)$ \\
Knee & $15(22.4)$ \\
Others & $14(20.9)$ \\
Upper extremity involvement & $9(13.4)$ \\
Wrist & $7(10.4)$ \\
Elbow & $1(1.5)$ \\
Others & $1(1.5)$ \\
No. of involved joints at attack & \\
1 & $33(49.3)$ \\
2 & $22(32.8)$ \\
3 & $8(11.9)$ \\
4 & $2(3.0)$ \\
5 & $2(3.0)$ \\
Attack at previously untargeted joints & $24(35.8)$ \\
Lower extremity involvement & $20(29.9)$ \\
First metatarsophalangeal joint & $4(6.0)$ \\
Ankle & $7(10.4)$ \\
Knee & $7(10.4)$ \\
Others & $8(11.9)$ \\
Upper extremity involvement & $4(6.0)$ \\
Wrist & $2(3.0)$ \\
Elbow & $1(1.5)$ \\
Others & $1(1.5)$ \\
\hline
\end{tabular}

*Mean (SD), 1.8 (1.0).

number of inflamed joints; (4) surgical factors such as the postsurgical starvation period, body sites involved in surgery and length of surgery; (5) features of gout attacks before surgery including the number and location of involved joints, presence of tophi and history of urinary stones; (6) medications for gout attack, including non-steroidal anti-inflammatory drugs (NSAIDs), colchicine and allopurinol; and (7) serum urate levels before surgery and at time of attack. Urate levels from 3 days before or after an attack were used, with preference given to those on the date of the attack whenever possible. For each control patient, the lowest level of urate within 20 days after surgery was used for postsurgical uric acid level.

\section{Statistical analysis}

We analysed the presurgical and postsurgical attacks of 67 patients and compared the demographics, medical backgrounds,

Table 2 Association between the sites involved before and after surgery

\begin{tabular}{lllc}
\hline $\begin{array}{l}\text { Affected site } \\
\text { (postsurgical attack) }\end{array}$ & $\begin{array}{l}\text { Presurgical } \\
\text { involvement }\end{array}$ & $\mathbf{n ~ ( \% ) *}$ & p Value \\
\hline MTP & MTP & $37 / 40(92.5)$ & 0.005 \\
non-MTP & & $14 / 23(60.9)$ & \\
Ankle & Ankle & $13 / 20(65.0)$ & 0.007 \\
Non-ankle & & $12 / 43(27.9)$ & \\
Knee & Knee & $9 / 14(64.3)$ & $<0.001$ \\
Non-knee & & $6 / 49(12.2)$ & \\
Wrist & Wrist & $5 / 7(71.4)$ & 0.001 \\
non-wrist & & $5 / 56(8.9)$ & \\
\hline
\end{tabular}

*Numbers are based on 63 cases in whom detailed information on the affected sites in presurgical and postsurgical periods are available.

MTP, metatarsophalangeal. uric acid levels and presurgical medications between the patients who experienced postsurgical gout attacks and the controls who had a history of gout but did not develop postsurgical gout.

The $\chi^{2}$ and Fisher exact tests were used for comparison of categorical data. Continuous values were expressed as mean (SD) and comparison was performed with the Student t test. For analysis of correlation, the Spearman correlation coefficient was used. Multiple logistic regression was used for the risk factor analysis. Candidate variables with $\mathrm{p}$ value $<0.05$ were chosen for multivariate analysis. Among the candidate variables, use of allopurinol was omitted because of a strong correlation with presurgical uric acid level. All statistical calculations were performed with SPSS V.12 (SPSS Inc., Chicago, Illinois USA).

\section{RESULTS}

\section{Clinical features of postsurgical gout attacks}

The clinical features of 67 postsurgical gout attacks are summarised in table 1 . Most of the attacks developed within 8 days after surgery (mean interval, 4.2 (3.1) days) and involved the lower extremity joints $(65 / 67,97.0 \%)$, especially the first metatarsophalangeal (MTP) joint (42/67, 62.7\%). The number of joints affected was positively correlated with the total number of previously involved joints $(r=0.281, p=0.026)$, which in turn was in correlation with the duration of gout $(r=0.254, p=0.007)$. The involved sites showed a significant association with the previously involved sites; those who developed postsurgical gout in the first MTP, ankle, knee and wrist joints respectively, more often had a previous history of gout in the same joint than those who developed gout in other joints (table 2).

The treatments for postsurgical gout included oral colchicines (34/62, 54.8\%), NSAIDs (20/62, 32.3\%) and/or intravenous or intra-articular steroid injections (12/62, 19.4\%). All treated patients responded adequately, and five patients resolved without treatment.

\section{Comparison of clinical data between patients and controls}

Table 3 shows the baseline clinical data of the patients and controls. Most of the patients and controls were male. Their mean ages, mean BMI and prevalence of the associated medical illnesses were similar between the patients and controls. Additionally, there was no significant difference in the clinical features of gout attacks that had been suffered before surgery, including duration of gout history, preferential sites, distribution and the numbers of involved joints.

Despite the similarities above, the presurgical uric acid level and its perisurgical changes were significantly different between the two groups. The patients showed significantly higher presurgical uric acid levels (8.5 (2.2) vs 7.1 (2.1) mg/dl, $\mathrm{p}<0.001)$ and more rapid and profound decrease of uric acid levels after surgery than the controls $(-2.5$ (1.6) vs -0.8 (1.8) $\mathrm{mg} / \mathrm{dl}, \mathrm{p}<0.001 ;-0.7$ (0.8) vs $-0.3 \quad(0.7) \mathrm{mg} / \mathrm{dl} / \mathrm{day}$, $\mathrm{p}=0.011$ ) (fig 1). The range and rate of decrease were strongly associated with presurgical uric acid levels $(r=-0.580$, $\mathrm{p}<0.001 ; \mathrm{r}=-0.424, \mathrm{p}<0.001)$.

Allopurinol was more frequently taken by control patients (19.4\% vs $44.6 \%, p=0.002)$ and presurgical intake of allopurinol was associated with the lower baseline serum uric acid levels (6.7 (2.4) vs 8.3 (2.1) mg/dl, p<0.001). Colchicine was taken more frequently in the control group $(6.0 \%$ vs $21.9 \%, p=0.011$, respectively). 
Table 3 Comparison of baseline data between the patients $(n=67)$ and controls $(n=67)$

\begin{tabular}{|c|c|c|c|}
\hline & \multicolumn{2}{|c|}{ Postsurgical attack } & \multirow[b]{2}{*}{ p Value } \\
\hline & Positive, n (\%) & Negative, $\mathbf{n}(\%)$ & \\
\hline \multicolumn{4}{|l|}{ Demographic data: } \\
\hline Age (years, mean (SD)) & $61.6(11.0)$ & $61.9(12.0)$ & 0.881 \\
\hline Gender (male) & $64(95.5)$ & $65(97.0)$ & 1.000 \\
\hline BMI $\left(\mathrm{kg} / \mathrm{m}^{2}\right.$, mean $\left.(\mathrm{SD})\right)$ & $24.5(2.7)$ & $24.9(3.1)$ & 0.484 \\
\hline Associated medical illness & $41(61.2)$ & $43(64.2)$ & 0.721 \\
\hline \multicolumn{4}{|l|}{ Hypertension } \\
\hline Dyslipidaemia & $15(22.4)$ & $16(23.9)$ & 0.838 \\
\hline Diabetes mellitus & $9(13.4)$ & $10(14.9)$ & 0.804 \\
\hline Chronic renal failure & $12(17.9)$ & $15(22.4)$ & 0.518 \\
\hline \multicolumn{4}{|l|}{ Features of presurgical gout arthritis: } \\
\hline Previous gout duration (years, mean (SD)) & $7.6(6.3)$ & $7.6(7.5)$ & 0.990 \\
\hline Number of previously involved joints (mean, SD)) & $2.5(1.8)$ & $2.2(1.4)$ & 0.305 \\
\hline \multicolumn{4}{|l|}{ Previously involved joints: } \\
\hline Lower extremity joints & $62 / 63(98.4)$ & $50 / 50(100)$ & 1.000 \\
\hline First MTP & $51 / 63(81.0)$ & $43 / 50(86.0)$ & 0.614 \\
\hline Ankle & 25/63 (39.7) & $19 / 50(38.0)$ & 0.855 \\
\hline Knee & 15/63 (23.8) & $12 / 50(24.0)$ & 1.000 \\
\hline Others & $10 / 63(15.9)$ & $10 / 50(20.0)$ & 0.625 \\
\hline Upper extremity joints & $10 / 63(15.9)$ & $5 / 50(10.0)$ & 0.414 \\
\hline Wrist & $10 / 63(15.9)$ & $2 / 50(4.0)$ & 0.063 \\
\hline Elbow & $1 / 63(1.59)$ & $2 / 50(4.0)$ & 0.583 \\
\hline Others & $0 / 63(0)$ & $2 / 50(4.0)$ & 0.194 \\
\hline Presence of tophi & $6(9.0)$ & 9/51 (17.6) & 0.175 \\
\hline History of urinary stones & $4(6.0)$ & $4(6.0)$ & 1.000 \\
\hline Erosion on radiographs & $11 / 47(23.4)$ & $7 / 23(30.4)$ & 0.954 \\
\hline \multicolumn{4}{|l|}{ Laboratory data: } \\
\hline Serum urate level (mg/dl, mean (SD)) & $8.5(2.2)$ & $7.1(2.1)$ & $<0.001$ \\
\hline \multicolumn{4}{|l|}{ Anti-gout medications before surgery: } \\
\hline Allopurinol & $13(19.4)$ & $29 / 65(44.6)$ & 0.002 \\
\hline Colchicine & $4(1.5)$ & $14 / 64(21.9)$ & 0.011 \\
\hline
\end{tabular}

BMI, body mass index; MTP, metatarsophalangeal.

Table 4 summarises surgical factors related to postsurgical gout attack. Lengths of operation and postoperative starvation periods were similar for both groups. However, patients more frequently underwent cancer surgeries than the controls $(p=0.003)$. Regarding the site of surgery, gastrointestinal surgery was more frequent in the patient group $(p=0.021)$.

\section{Risk factors for postsurgical gout}

In univariate analysis, higher presurgical serum urate level $(p<0.001)$, cancer surgery $(p=0.003)$, or gastrointestinal surgery $(p=0.021)$ was associated with development of postsurgical gout while presurgical intake of colchicine $(p=0.011)$ or allopurinol $(p=0.002)$ was more frequent in

Table 4 Surgical procedures performed on patients $(n=67)$ and controls $(n=67)$

\begin{tabular}{lccc}
\hline & \multicolumn{2}{l}{ Postsurgical attack } & \\
\cline { 2 - 3 } & Positive, $\mathbf{n}(\%)$ & Negative, $\mathbf{n}(\%)$ & p Value \\
\hline Operation time (h, mean (SD)) & $4.5(2.3)$ & $4.6(3.8)$ & 0.931 \\
Postoperative starvation (days, mean (SD)) & $4.4(7.4)$ & $3.8(3.9)$ & 0.529 \\
Cancer surgery (\%) & $40(59.7)$ & $23(34.3)$ & 0.003 \\
Surgical sites: & & & \\
$\quad$ Intracranial & $1(1.5)$ & $1(1.5)$ & 1.000 \\
Head and neck & $3(4.5)$ & $7(10.4)$ & 0.325 \\
Heart and lungs & $8(11.9)$ & $11(16.4)$ & 0.456 \\
Vascular & $4(6.0)$ & $6(9.0)$ & 0.744 \\
Hepatobiliary & $3(4.5)$ & $10(14.9)$ & 0.077 \\
Gastrointestinal & $32^{*}(47.8)$ & $19^{*}(28.3)$ & 0.021 \\
$\quad$ Urogenital & $9(13.4)$ & $3(4.5)$ & 0.128 \\
$\quad$ Musculoskeletal & $8(11.9)$ & $8(11.9)$ & 1.000 \\
$\quad$ Others & $2(3.0)$ & $3(4.5)$ & 1.000 \\
\hline
\end{tabular}

${ }^{*}$ Among the 32 patients and 19 controls who underwent gastrointestinal surgeries, 4 and 1 also underwent urogenital surgeries respectively. They are represented in both groups for this table. 


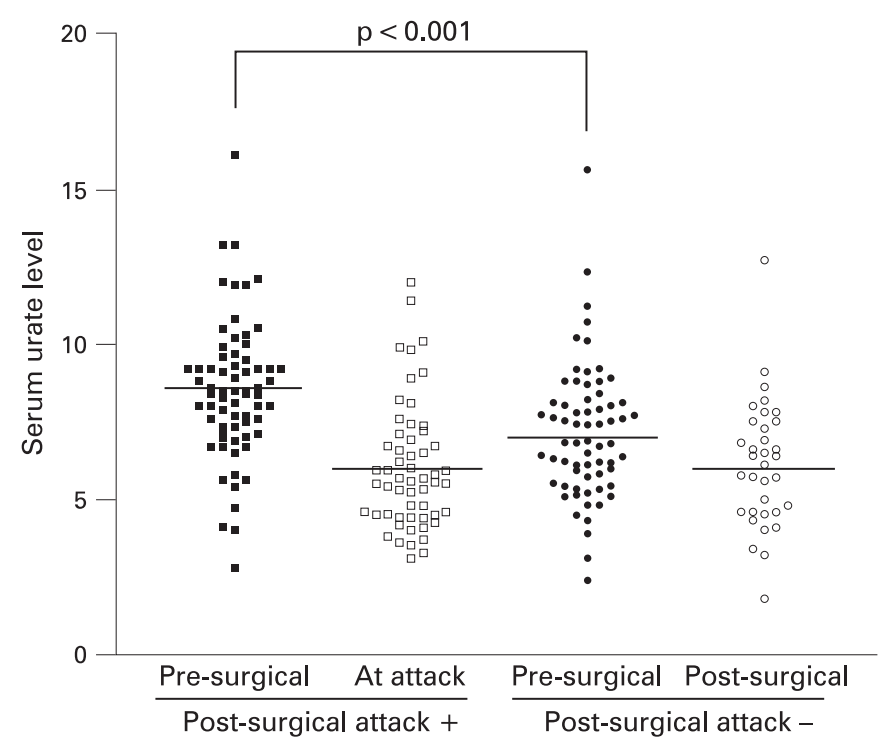

Figure 1 Comparison of uric acid levels between patients with postsurgical gout attack and without postsurgical attack. Presurgical uric acid level was significantly higher in patients with attack $(p<0.001)$ and was correlated with drop of uric acid levels after surgery $(r=-0.580$, $\mathrm{p}<0.001)$.

control patients $(p=0.011)$ (tables 3 and 4 , supplementary tables 1 and 2). Cancer surgery, presurgical urate levels of $\geqslant 9 \mathrm{mg} / \mathrm{dl}$ and the absence of colchicine prophylaxis were identified as significant risk factors $(p=0.002, p=0.002$, $p=0.008$, respectively) for postsurgical gout attack in multivariate analysis (table 5 ).

\section{DISCUSSION}

The clinical features of gout attacks in the postsurgical period in this study were as follows: (1) most of the attacks appear within 8 days after surgery; (2) lower extremity joints (97\%), particularly the first MTP joints (62.7\%), were most frequently involved; (3) less than half of cases $(49.3 \%$ ) presented as a monoarticular attack; (4) the number of joints affected in postsurgical attack were correlated with the total number of previously involved joints; and (5) although new joints were affected in about a third of cases (35.8\%), the site of attacks had, in general, a preference for the previously affected sites. These findings suggest that the features of postsurgical gout reflect the features of gout arthritis the patient has suffered before surgery. The fact that the patients had a previous gout history (on average for 7.6 years before the surgery) explains why the postsurgical gout that developed in these patients was more similar to advanced rather than early phase gout, in which recurrent monoarticular attack on the first MTP joint is typical. Another possible reason why postsurgical attacks tended to be polyarticular and often involve non-first MTP joints is that the pathogenic trigger mechanisms of gout attack may differ in surgical and non-surgical conditions. While local factors such as cold temperature or a minor trauma in the first MTP joint precipitate attacks, ${ }^{14}$ certain systemic factors that become prevalent after surgery may instigate attacks in several joints simultaneously.

When compared, patients and controls showed similar demographics and medical backgrounds except there were more cancer cases in the former group. Moreover, the clinical features of previous gout arthritis were also similar for both groups in
Table 5 Multivariate analysis of risk factors for postsurgical gout

\begin{tabular}{|c|c|c|}
\hline & Odds ratio $(95 \% \mathrm{CI})$ & p Value \\
\hline \multicolumn{3}{|c|}{ Presurgical uric acid level $(\mathrm{mg} / \mathrm{dll})$ : } \\
\hline $6-7$ & $0.558(0.127$ to 2.458$)$ & 0.441 \\
\hline $7-8$ & $1.347(0.358$ to 5.065$)$ & 0.659 \\
\hline $8-9$ & $2.227(0.635$ to 7.806$)$ & 0.211 \\
\hline$\geqslant 9$ & 8.245 (2.226 to 30.544$)$ & 0.002 \\
\hline Gastrointestinal surgery & 0.635 (0.199 to 2.033$)$ & 0.445 \\
\hline Cancer surgery & 6.185 (1.922 to 19.903$)$ & 0.002 \\
\hline Colchicine prophylaxis & $0.157(0.040$ to 0.612$)$ & 0.008 \\
\hline
\end{tabular}

terms of duration of gout, preferential sites, distribution, and the number of previously affected joints. This suggests that postsurgical gout does not develop in relation to a specific feature of previous gout arthritis (tables 3 and 4).

The risk factors for postsurgical gout attack identified by multivariate analysis were cancer surgery, presurgical urate level $\geqslant 9 \mathrm{mg} / \mathrm{dl}$ and the absence of colchicine prophylaxis. Cancers, especially haematological malignancies, are known to cause hyperuricaemia and gout due to high rates of cellular turnover. ${ }^{15}{ }^{16}$ However, basal serum urate levels were not significantly different between patients with cancer and patients without cancer, nor were perisurgical changes in urate level in our study (data not shown), suggesting that triggering factors other than hyperuricaemia are involved. Increased chemokine levels in patients with cancer might condition monocytes for engulfing monosodium urate crystals. ${ }^{17}{ }^{18}$ Despite this plausible speculation, the association between cancer surgery and postsurgical gout observed in this study does not allow us to directly relate cancer surgery or cancer as a reason for surgery to lead to development of a gout attack because of the retrospective and cross-sectional nature of the study

As seen in tables 3 and 4 , the presurgical serum level of uric acid was the most important risk factor. The risk of attack increased in proportion to presurgical uric acid levels (table 5). This is consistent with more prevalent allopurinol intakes, lower uric acid levels and lower frequency of postsurgical attacks observed in the control group. In some controls, longterm allopurinol intake might have caused urate crystal dissolution, making it impossible to develop gout. ${ }^{19}$ These findings are important because they suggest that postsurgical gout attacks can be prevented by controlling presurgical uric acid levels.

Surgery has long been suspected as a precipitating factor of gout attack, and surgical procedures include several factors that can increase serum uric acid levels, including starvation, dehydration and tissue hypoxia. ${ }^{20-22}$ However, in our study, most patients and controls showed decrease of urate levels during the perisurgical period, and patients showed a more rapid and profound drop in urate levels than did controls. Moreover, the rate and range of drop were well correlated with the presurgical serum urate levels. Our results are consistent with the hypothesis that the triggering factor for a gout attack is a dramatic change in uric acid levels rather than absolute level of initial uric acid. ${ }^{23}{ }^{24} \mathrm{~A}$ rapid drop of uric acid levels after surgery might be due to the low sodium loading in infusion fluid during the perisurgical period. Lower sodium content in infusion fluid may prevent resorption of filtered urate in the renal proximal tubule, which is coupled with a sodium-dependent organic acid co-transporter. ${ }^{25}$ This speculation is consistent with the finding 
that patients with higher presurgical uric acid levels showed larger drops in these levels, because they had greater luminal urate loading and therefore were more prone to urinary urate loss due to impaired urate resorption.

Gastrointestinal surgery was associated with postsurgical attack in univariate analysis. Recently, the role of innate immunity in gout pathogenesis has been revealed, including toll-like receptor (TLRs) 2 and 4 and the cryopyrin pathway. ${ }^{26}{ }^{27}$ Because peptidoglycan and lipopolysaccharide are also ligands for TLRs 2 and 4, respectively, ${ }^{28}$ subtle bacteraemia during gastrointestinal surgery might condition these TLRs to be more easily activated.

Our results suggest ways in which postsurgical gout may be prevented in patients with gout undergoing surgery with general anaesthesia. Serum uric acid levels should be maintained below $9 \mathrm{mg} / \mathrm{dl}$, preferably less than $7 \mathrm{mg} / \mathrm{dl}$. Colchicine prophylaxis should be considered in patients who are not candidates for lowering of their serum uric acid level. Doctors caring for postsurgical patients with a history of gout should maintain a high clinical suspicion for gout so that early treatment may be provided.

Acknowledgements: We would like to thank Professors Cornelia M Weyand and Jörg J Goronzy for their helpful comments. We would also like to thank the Medical Research Collaboration Center in Seoul National University College of Medicine for professional statistical support.

Funding: This study was supported by a grant of the Korea Health 21 R\&D Project from the Ministry of Health \& Welfare, Republic of Korea (03-PJ10-PG13-GD01-0002).

Competing interests: None declared.

\section{REFERENCES}

1. Underwood M. Diagnosis and management of gout. BMJ 2006;332:1315-9.

2. Wallace KL, Riedel AA, Joseph-Ridge N, Wortmann R. Increasing prevalence of gout and hyperuricemia over 10 years among older adults in a managed care population. $J$ Rheumatol 2004;31:1582-7.

3. Arromdee E, Michet CJ, Crowson CS, O'Fallon WM, Gabriel SE. Epidemiology of gout: is the incidence rising? J Rheumatol 2002;29:2403-6.

4. Krishnan E, Baker JF, Furst DE, Schumacher HR. Gout and the risk of acute myocardial infarction. Arthritis Rheum 2006;54:2688-96.

5. Becker MA, Jolly M. Clinical gout and the pathogenesis of hyperuricemia. In: Koopman WJ, Moreland LW, eds. Arthritis and allied conditions, 15th edn. Philadelphia, Pennsylvania, USA: Lippincott Williams \& Wilkins, 2005: 2303-39.

6. Choi HK, Atkinson K, Karlson EW, Willett W, Curhan G. Alcohol intake and risk of incident gout in men: a prostpective study. Lancet 2004;363:1277-81.

7. Zhang Y, Woods R, Chaisson CE, Neogi T, Niu J, McAlindon TE, et al. Alcohol consumption as a trigger of recurrent gout attacks. Am J Med 2006;119:e13-8.

8. Craig MH, Poole GV, Hauser CJ. Postsurgical gout. Am Surg 1995;61:56-9.
9. Siu AL, Penrod JD, Boockvar KS, Koval K, Strauss E, Morrison RS. Early ambulation after hip fracture: effects on function and mortality. Arch Intern Med 2006;166:766-71.

10. Tsunoda A, Shibusawa M, Takata M, Hiratsuka K, Shida K, Kusano M. Early oral feeding should be resumed following the resolution of gastric ileus. Hepatogastroenterology 2005;52:775-9.

11. Oldmeadow LB, Edwards ER, Kimmel LA, Kipen E, Robertson VJ, Bailey MJ. No rest for the wounded: early ambulation after hip surgery accelerates recovery. ANZ J Surg 2006;76:607-11.

12. Delaney CP, Zutshi M, Senagore AJ, Remzi FH, Hammel J, Fazio VW. Prospective, randomized, controlled trial between a pathway of controlled rehabilitation with early ambulation and diet and traditional postoperative care after laparotomy and intestinal resection. Dis Colon Rectum 2003:46:851-9.

13. Linton RR, Talbott JH. The surgical treatment of tophaceous gout. Ann Surg 1943;117:161-82.

14. McCarty DJ. Gout without hyperuricemia. JAMA 1994;271:302-3.

15. Crittenden DR, Ackerman GL. Hyperuricemic acute renal failure in disseminated carcinoma. Arch Intern Med 1977;137:97-9.

16. Gold GL, Fritz RD. Hyperuricemia associated with the treatment of acute leukemia Ann Intern Med 1957;47:428-34.

17. Baier PK, Eggstein S, Wolff-Vorbeck G, Baumgartner U, Hopt UT. Chemokines in human colorectal carcinoma. Anticaner Res 2005;25:3581-4.

18. Kershaw MH, Wang G, Westwood JA, Pachynski RK, Tiffany HL, Marincola FM, et al. Redirecting migration of T cells to chemokine secreted from tumors by genetic modification with CXCR2. Hum Gene Ther 2002;13:1971-80.

19. Zhang W, Doherty M, Bardin T, Pascual E, Barskova V, Conaghan P, et al. EULAR evidence based recommendations for gout. Part II: Management. Report of a task force of the EULAR Standing Committee for International Clinical Studies Including Therapeutics (ESCISIT). Ann Rheum Dis 2006;65:1312-24.

20. Ogryzlo MA. Hyperuricemia induced by high fat diets and starvation. Arthritis Rheum 1965:8:799-822.

21. Feinstein El, Quion-Verde H, Kaptein EM, Massry SG. Severe hyperuricemia in patients with volume depletion. Am J Nephrol 1984;4:77-80.

22. Woolliscroft J0, Colfer $\mathrm{H}$, Fox $\mathbf{H}$. Hyperuricemia in acute illness: a poor prognostic sign. Am J Med 1982;72:58-62.

23. Terkeltaub RA. Pathogenesis and treatment of crystal-induced inflammation. In: Koopman WJ, Moreland LW eds. Arthritis and allied conditions, 15th edn. Philadelphia, Pennsylvania, USA: Lippincott Williams \& Wilkins, 2005: 2357-72.

24. Vandenberg MK, Moxley G, Breitbach SA, Roberts WN. Gout attacks in chronic alcoholics occur at lower serum urate levels than nonalcoholics. J Rheumatol 1994:21:700-4.

25. Enomoto A, Kimura H, Chairoungdua A, Shigeta Y, Jutabha P, Cha SH, et al. Molecular identification of a renal urate anion exchanger that regulates blood urate levels. Nature 2002:417:447-52.

26. Liu-Bryan R, Scott P, Sydlaske A, Rose DM, Terkeltaub R. Innate immunity conferred by Toll-like receptors 2 and 4 and myeloid differentiation factor 88 expression is pivotal to monosodium urate monohydrate crystal-induced inflammation. Arthritis Rheum 2005;52:2936-46.

27. Martinon F, Pétrilli V, Mayor A, Tardivel A, Tschopp J. Gout-associated uric acid crystals activate the NALP3 inflammasome. Nature 2006;440:237-41.

28. Poltorak A, He X, Smirnova I, Liu MY, Van Huffel C, Du X, et al. Defective LPS signaling in $\mathrm{C} 3 \mathrm{H} / \mathrm{HeJ}$ and $\mathrm{C} 57 \mathrm{BL} / 10 \mathrm{ScCr}$ mice: mutations in Tlr4 gene. Science 1998;282:2085-8.

29. Takeuchi 0, Hoshino K, Kawai T, Sanjo H, Takada H, Ogawa T, et al. Differential roles of TLR2 and TLR4 in recognition of gram-negative and gram-positive bacteria cell wall components. Immunity 1999;11:443-51. 